\title{
Conceptualising sustainability through environmental stewardship and virtuous cycles-a new empirically-grounded model
}

\author{
John W. Turnbull ${ }^{1}$ (D) Graeme F. Clark $^{1}$ (D) Emma L. Johnston ${ }^{1}$ (D)
}

Received: 21 September 2020 / Accepted: 26 May 2021 / Published online: 9 June 2021

(c) The Author(s) 2021

\begin{abstract}
Humans depend on earth's ecosystems and in the Anthropocene, ecosystems are increasingly impacted by human activities. Sustainability—-the long-term integrity of social-ecological systems-depends on effective environmental stewardship, yet current conceptual frameworks often lack empirical validation and are limited in their ability to show progress towards sustainability goals. In this study we examine institutional and local stewardship actions and their ecological and social outcomes along $7000 \mathrm{~km}$ of Australia's coastline. We use empirical mixed methods and grounded theory to show that the combination of local and institutional stewardship leads to improved ecological outcomes, which in turn enhance social values and motivate further stewardship to form a virtuous cycle. Virtuous cycles may proceed over multiple iterations, which we represent in a new spiral model enabling visualisation of progress towards sustainability goals over time. Our study has important implications for collaborative earth stewardship and the role of policy in enabling virtuous cycles to ultimately realise sustainable futures.
\end{abstract}

Keywords Sustainability · Social-ecological systems · Environmental stewardship · Mixed methods · Grounded theory · Sustainable development goals

\section{Introduction}

We are inseparable from our environment. Humans depend on nature to provide the essentials of life, and in turn, environmental health is heavily dependent on the actions of humans (Preiser et al. 2017; Steffen et al. 2011). The fundamental importance and mutuality of human-environment relationships is embodied in the concept of sustainability-the "long-term integrity of the biosphere and human well-being" (Chapin et al. 2011). Despite the criticality of

Handled by Georgina Gurney, Australian Research Council Centre of Excellence for Coral Reef Studies, James Cook University, Australia.

John W. Turnbull

john.turnbull@unsw.edu.au

Graeme F. Clark

g.clark@unsw.edu.au

Emma L. Johnston

e.johnston@unsw.edu.au

1 University of NSW, BEES, Anzac Pde, Kensington, NSW, Australia human-environment relationships, we have much yet to learn of the modern structures, interactions and dynamics of social-ecological systems (Messerli et al. 2019; Scholz and Binder 2011).

A key element in achieving a sustainable future is for humans to take responsibility as environmental stewards (Steffen et al. 2011; Preiser et al. 2017). Whilst stewardship is just one of several framings for the human-environment relationship, it most closely supports reconnecting people with nature and building resilience in social-ecological systems (Preiser et al. 2017). Environmental stewardship is a fluid concept (Turnbull et al. 2020a); here we define it as active earth-keeping, taking responsibility to protect, care for and use the environment for positive ecological and social outcomes (Lerner 1993; Bennett et al. 2018).

The United Nations 2030 Agenda for Sustainable Development provides a plan of stewardship action "for people, planet and prosperity" (DESA UN 2016). This social-ecological Agenda seeks to end inequality and poverty, and heal and secure our planet for a sustainable future. It is actioned through 17 Sustainable Development Goals (SDGs) and 169 targets, many of which connect humans and nature. Yet today, most SDGs are projected to fall short of their targets, 
with several goals currently on negative trajectories (UN Secretary General 2019).

Converting negative trajectories to positive, to achieve our global sustainability Agenda, will require new ways of thinking and acting (UN Secretary General 2019). Novel inter-disciplinary approaches such as integrating science, business and government, informed by improved knowledge networks and resulting in collaborative management, are required (Messerli et al. 2019). Such societal transformations will depend on new conceptualisations of the human-environment relationship, as today most theoretical social-ecological models have limited application (Binder et al. 2013).

Protected areas can provide places which facilitate environmental stewardship, resulting in improved social and ecological values (Powell et al. 2002). Protected areas may exist in both terrestrial and marine realms and have varying levels of protection or stewardship (Dudley et al. 2013). Fully protected areas, for example, prohibit the removal of or damage to all animals and plants. Partially protected areas have widely varying regulations but allow a range of extractive activities to occur including fishing and collecting. Such differing levels of stewardship can result in varying levels of ecological and social effectiveness (Turnbull et al. 2021).

In this study, we aimed to develop a novel conceptualisation of the human-environment relationship, focusing on the positive actions human society may take towards sustainability. We explored the concepts of environmental stewardship and virtuous cycles and investigated whether these concepts were supported by empirical evidence. We studied both institutional stewardship-in the form of varying levels of protection-and the individual or local environmental stewardship actions of people at a place (Turnbull et al. 2020a).

Our approach was to examine a diverse social-ecological system to provide insight into broader-scale trajectories towards sustainability. To achieve this, we selected coastal places as they integrate terrestrial and marine realms and provide a linked system of social and ecological dynamics (Pollnac et al. 2010). We chose Australia's Great Southern Reef coastline, spanning five jurisdictions and $7000 \mathrm{~km}$ for our study due to its size, diversity and ecological importance (Bennett et al. 2016).

\section{Frameworks and models}

Human-ecosystem relationships can be visualised through multiple frameworks including unidirectional (such as ecosystem services or stewardship alone), bidirectional (such as closed loop production), and intersecting or nested domains (Fig. 1) (Folke et al. 2016; Moskell and Allred 2013; Raymond et al. 2013). Selection of a given framework both highlights and hides elements, preferencing one set of perspectives, ethics and outcomes over another (Preiser et al. 2017; Raymond et al. 2013). The closed-loop framework, expanded beyond production to encompass values, services and dis-services, as well as positive and negative human impacts on ecosystems, has some limitations yet has potential for broad application (Masterson et al. 2019; Raymond et al. 2013). It is manifest in varying degrees in a number of existing systems models or derivative frameworks. We now discuss three such derivative frameworks, selected to illustrate the diverse yet still limited practical applications of the general closed-loop framework.

The DPSIR framework-driving forces, pressures, states, impacts, and responses (Smeets 1999) — is a widely used framework for environmental indicators. DPSIR models a mostly one-way flow from Drivers such as industry, to Pressures such as pollution, State of environment such as water quality and Impacts such as loss of biodiversity or drinking water. The final step, Response, closes the loop with a human intervention to mitigate impacts, states, pressures and drivers through actions such as wastewater treatment. The language of DPSIR is focused on the negative impacts of humans on the environment although it may be applied in the context of sustainability with the use of suitable indicators (Smeets 1999).

The Human-Environment Systems (HES) framework (Scholz and Binder 2011) focuses on managing the negative impacts of humans on the environment but with explicit recognition of the reciprocal impact of environmental factors on humans. HES is grounded in the social and sustainability sciences and decision theory, and enables the general formation of goals and strategies to manage the human-environment relationship (Scholz and Binder 2011; Binder et al.
Fig. 1 Frameworks for humanecosystem relationships. a unidirectional, b bidirectional, and $\mathbf{c}$ nested a

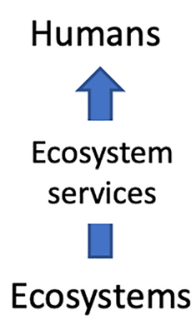

b

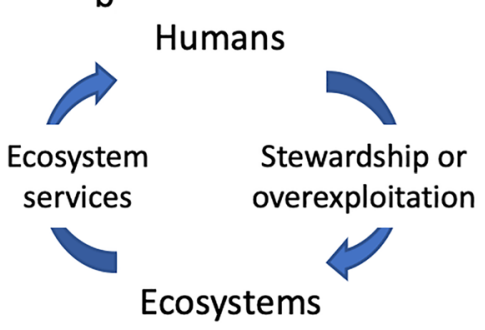

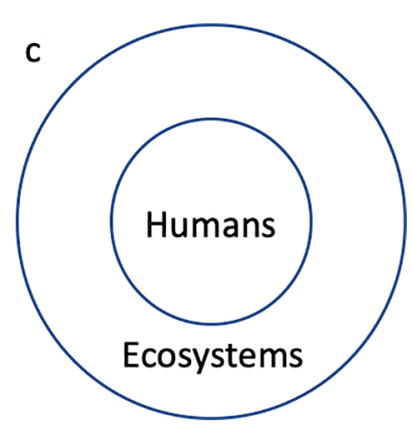


2013). It models primary and secondary feedback loops for the evaluation of environmental responses and dynamics arising from these strategies. The HES framework does not contain a sustainability component, but it can be used to investigate sustainability learning in a given context (Scholz and Binder 2011).

The Social-Ecological Systems Framework (SESF) is balanced in its treatment of social and ecological subsystems but takes an anthropocentric perspective that views ecological components as resources (Ostrom 2009). This is reflected in its application in the management of agriculture, fisheries and water resources. It acknowledges the governance system and resource "users", with feedback loops for the social and ecological outcomes arising from system interactions. As with HES, the SESF does not explicitly contain a sustainability component but can be used to analyse sustainability of the social-ecological system (Ostrom 2009).

The originating context, perspective and assumptions for each of the above frameworks are manifest in the specific language and limitations of each framework, often resulting in a focus on the negative or exploitative aspects of the human-environment relationship. In our study, we aim to develop a model, grounded on empirical evidence, which highlights the positive actions that humans can take to drive upward trajectories in both environmental health and human well-being. This virtuous circle or cycle has potential as a basis for such a model; however, this concept has been used in varying, sometimes differing ways in both the academic and management literature.

Early research regarding the virtuous circle or cycle proposed a model in which social and ecological capital were mutually reinforced and concluded that a key objective of policy should be to achieve "virtuosity in the landscape" (Selman and Knight 2006). Qualitative, trans-disciplinary approaches were considered necessary to fully appreciate the interdependency between "people and place" and develop representative models (Selman and Knight 2006). Protected areas were recognised as pivotal in achieving virtuosity, leading to sustainability improvements in both landscape quality and community quality of life (Powell et al. 2002), although recent research highlights the difficulty in simultaneously meeting social and ecological goals in coastal settings (Cinner et al. 2020).

Tidball et al. (2017) applied virtuous and vicious cycles to develop the concept of resilience in social-ecological systems. They used systems theory, in which positive feedback amplifies change and negative feedback inhibits or counterbalances change. Virtuous and vicious cycles were, therefore, both positive or reinforcing feedback loops, but driving the system in desirable or undesirable directions. The definition of desirable vs. undesirable is value laden (Preiser et al. 2017), but in terms of sustainability these could be represented by, for example, endemic biodiversity preservation vs. loss, and the gain or loss of human wellbeing. The authors placed desirable states in the virtuous domain and undesirable states in the vicious domain, with a bifurcation zone between which may tip in either direction based on policy and management actions. They encouraged future research to detect the practices contributing to virtuous cycles and provide evidence of the resulting social and ecological outcomes.

Masterson et al. (2019) most recently conceptualised the relationship between ecosystems and human wellbeing as a holistic cycle that can be either positive (virtuous), or negative. The virtuous cycle results from effective stewardship, whilst the negative cycle results from overexploitation of the environment and poor management. The model integrates human values, attitudes and actions and recognises the mediating role of institutions and policy in the cycle. Human benefits are modelled broadly as a "basket" of direct use, monetary income and experiences. In presenting this broad conceptual model, the authors call for further empirical research to understand and verify components of the cycle.

The recent Global Sustainable Development Report (UN Secretary General 2019) mentions transforming "vicious to virtuous circles" but offers no conceptual basis for these terms. Virtuous circles are not explained, but vicious circles are referenced in the context of negative tipping points in Earth's natural systems and the acceleration of global warming through melting sea ice and permafrost. Importantly, eleven of the seventeen SDGs embody one or both directions of the virtuous circle, in the general form of humans caring for, or benefitting from, the environment (Table 1). Ultimately, the vicious-to-virtuous transformation is described as "key to the implementation of the 2030 Agenda" (UN Secretary General 2019).

Existing social-ecological and virtuous cycle models only partly enable visualisation of such transformation. They generally focus on the relationship between components in the social-ecological system, but do not directly incorporate the concept of sustainability nor allow visualisation of positive progress towards sustainability over time. This would require representation of both a direction-towards (or away from) the goal; and time-as current sustainable development goals are set for a given year (DESA UN 2016). Tidball et al.'s (2017) model does include a graphical landscape which enables visualisation the system state between virtuous and vicious domains, but with the goal of resilience rather than sustainability. There is, therefore, an opportunity to further conceptualise the positive pathways through stewardship and virtuous cycles to sustainability (Chapin et al. 2011; Mathevet et al. 2018). 
Table 1 Sustainable Development Goal (SDG) components which relate to the virtuous cycle; humans caring for or benefitting from the environment (stewardship and social values or ecosystem services, respectively)

\begin{tabular}{|c|c|c|c|}
\hline SDG & Goal & Stewardship components & Social values/services components \\
\hline 1 & No poverty & & Access to natural resources \\
\hline 2 & Zero hunger & Maintain ecosystems & Sustainable food production \\
\hline 5 & Gender equality & & Access to natural resources \\
\hline 6 & Clean water and sanitation & Protect and restore water-related ecosystems & \\
\hline 8 & Decent work and economic growth & $\begin{array}{l}\text { Decouple economic growth from environmental deg- } \\
\text { radation }\end{array}$ & \\
\hline 9 & Industry, innovation and infrastructure & $\begin{array}{l}\text { Greater adoption of clean and environmentally sound } \\
\text { technologies }\end{array}$ & \\
\hline 11 & Sustainable cities and communities & $\begin{array}{l}\text { Protect the world's natural heritage } \\
\text { Reduce environmental impact of cities }\end{array}$ & Accessible green spaces \\
\hline 12 & Responsible consumption and production & $\begin{array}{l}\text { Sustainable management of natural resources } \\
\text { Environmentally sound management of wastes }\end{array}$ & $\begin{array}{l}\text { Efficient use of natural resources } \\
\text { Lifestyles in harmony with nature }\end{array}$ \\
\hline 13 & Climate action & Meaningful mitigation & Resilience to climate-related hazards \\
\hline 14 & Life below water & $\begin{array}{l}\text { Protect and conserve marine and coastal ecosystems } \\
\text { Reduce marine pollution } \\
\text { End unsustainable fishing practices } \\
\text { Conserve at least } 10 \% \text { of coastal and marine areas } \\
\text { Increase scientific knowledge to improve ocean health } \\
\text { Enhance conservation through international law }\end{array}$ & $\begin{array}{l}\text { Sustainable use of healthy, produc- } \\
\text { tive oceans } \\
\text { Increase benefits of marine resources } \\
\text { to small and undeveloped nations } \\
\text { Contribution of marine biodiversity } \\
\text { to development } \\
\text { Access for small-scale artisanal } \\
\text { fishers }\end{array}$ \\
\hline 15 & Life on land & $\begin{array}{l}\text { Protect and restore terrestrial ecosystems } \\
\text { Conserve and halt loss of biodiversity } \\
\text { Protect threatened species } \\
\text { Reduce the impact of invasive species } \\
\text { Halt deforestation, increase reforestation } \\
\text { Combat desertification and land degradation }\end{array}$ & $\begin{array}{l}\text { Sustainable use of terrestrial eco- } \\
\text { systems } \\
\text { Improve capacity for benefit from } \\
\text { natural ecosystems } \\
\text { Fair and equitable benefit from } \\
\text { genetic resources } \\
\text { Integrate ecosystem and biodiversity } \\
\text { values in planning and develop- } \\
\text { ment } \\
\text { Pursue sustainable livelihood oppor- } \\
\text { tunities }\end{array}$ \\
\hline
\end{tabular}

Components were extracted from the UN 2030 Agenda SDG target descriptions, where these made reference to either environmental stewardship-related actions or social values/ecosystem services (DESA, UN (2016)

\section{Methods}

\section{Approach}

Our research along Australia's Great Southern Reef spanned the southern half of the continent of Australia, from Port Stephens to Perth. We studied 56 sites, spanning five jurisdictions (States), with roughly even distribution across protected area levels to model different policy (institutional stewardship) settings; 19 sites were fully protected areas, 18 sites were partially protected areas and 19 sites were open areas (Fig. 2 and Table S1). We selected site boundaries to encompass the diversity of recreational uses observed at the site and a mix of terrain such as water, rocky shore, beach, parkland and other developed areas, where they were present.

Our social-ecological research questions called for a diverse set of methods. We used structured observation
(Bryman 2016) to record site factors such as mix of users (people swimming, walking, fishing etc) and signage. Perceptions, values, motivations and recreational and stewardship activities of individuals at each site were gathered using semi-structured interviews (Bryman 2016). We used purposive sampling, selecting people in proportion to the numbers in each user category at each site (Table S3), and aiming for representation of sex and age classes where possible. At several of our sites, the numbers of people present were small, allowing sampling of most or even all users.

We chose underwater visual census as implemented in the global Reef Life Survey (RLS) program for the ecological part of our study (RLS 2016). RLS uses highly trained volunteers and scientists to gather fish, invertebrate and habitat data on shallow reefs, and has been used in many studies around the world (for example, Edgar et al. 2014). RLS data include size-classed abundances of all visible fishes, abundances of all visible mobile macroinvertebrates, and 
Fig. 2 Study sites spanning five States (jurisdictions) in southern Australia. Numbers indicate the number of sites in each region

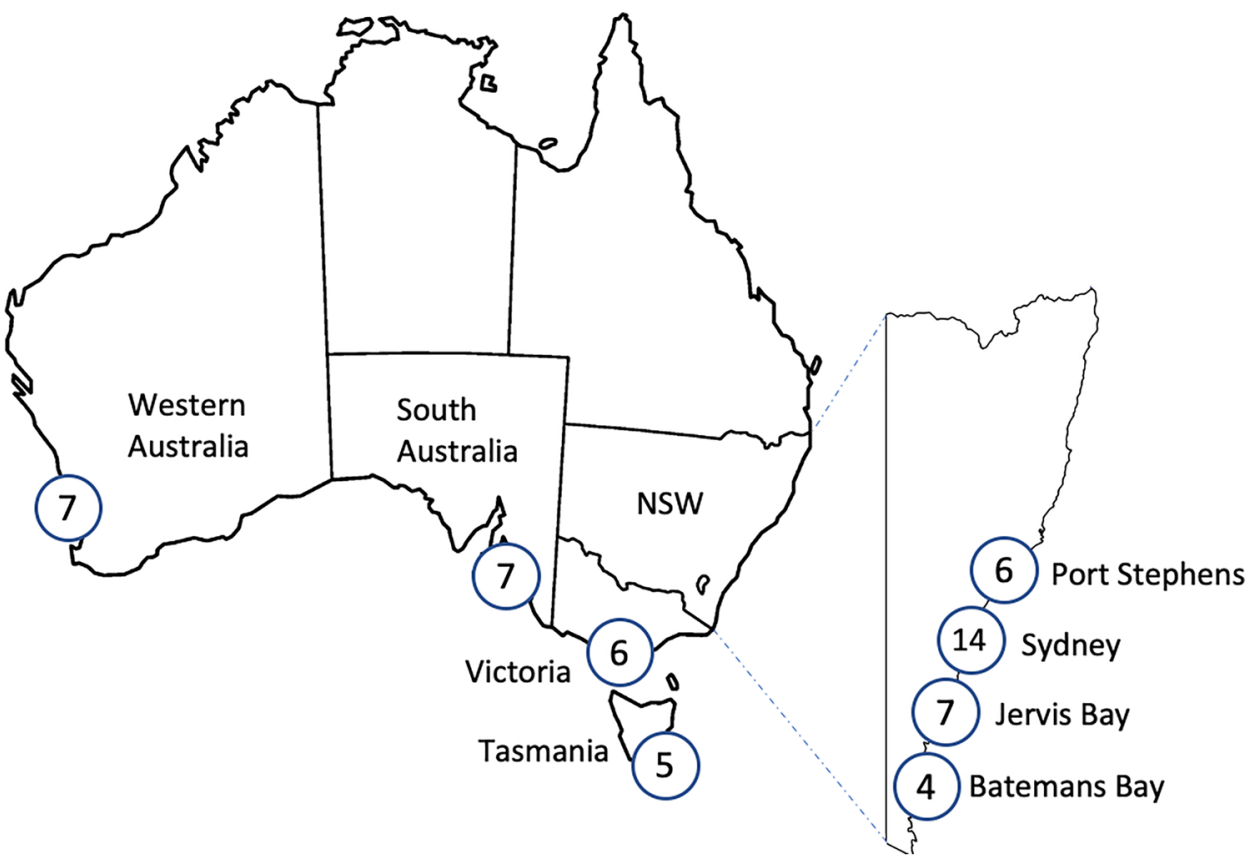

twenty photo-quadrats of habitat along each $50 \mathrm{~m}$ transect. We verified that the RLS dataset contained ecological data aligned with the top three categories of marine life that were mentioned as important by participants in interviews; fish, algae and seagrass (habitat data set) and marine mammals (included in the "fish" data set).

\section{Data collection}

We gathered social data over a 15-month period commencing in March 2018. Due to the practical limitations inherent in covering large distances in Australia, we travelled primarily from east to west, surveying NSW then Victoria, Tasmania, South Australia and Western Australia. To check for the influence of seasonal effects, we completed our final site and social surveys once we had looped back to NSW and confirmed that site usage figures did not vary significantly by season (PERMANOVA $p>0.05$ ). In total, 190 site surveys and 439 interviews were conducted during daylight hours over a mix of weekdays and weekends. The interview guide is provided in Table S2. We prompted for stewardship activities using the categories in the Local Environmental Stewardship Indicator (Turnbull et al 2020b and Table 2). The average duration of each site visit was $97 \mathrm{~min}$. Interviews, which typically took $15 \mathrm{~min}$ each but in some cases lasted up to $45 \mathrm{~min}$, passed the point of theoretical saturation by the end of the project (Bryman 2016).

Due to the large public Reef Life Survey database we were able to incorporate retrospective ecological data spanning 6 years. We chose this period as a balance between the duration of participants' experience at a site and the duration of our study. We included a total of 625 RLS fish surveys, 556 invertebrate surveys and 1971 photo quadrats in our study.

\section{Analysis}

Our approach followed grounded theory, one of the most widely applied analytical approaches in the study of qualitative data (Bryman 2016), identifying and developing concepts via structured analysis and inductive reasoning over the course of our research (Glaser et al. 1968). We evaluated: the perceptions, values, motivations and stewardship actions of people; policy settings in the form of levels of protection; and ecological health factors including biodiversity and abundance of fish, invertebrates and algae at each site.

We used a combination of indicators incorporating Likert scales (agreement/disagreement), frequency scales (how often an activity was performed or observed) and categorical coding of open and closed questions during each interview (Bryman 2016). Responses to open questions were recorded by a combination of audio recordings and in situ written transcripts and were later coded and analysed in nVivo software version 12 (QSR 2018). Further classifications were created, for example locals vs. visitors, based on self-reporting or observation. Signage was classified as compliance (e.g., relating to fishing regulations) or marine life (e.g., celebrating the local fauna).

To understand relationships between social factors and ecological condition, we conducted Gaussian linear mixed-effects models (LMM) via the LME4 package in $\mathrm{R}$ ( $\mathrm{R}$ Core Team 2018). Response variables were the 
Table 2 Stewardship action categories, proportion of participants who reported actions in each category (\%), and examples of quotations (with participant reference number)

\begin{tabular}{|c|c|c|}
\hline Stewardship category & $\%$ & Example quotations \\
\hline Sustainable use & 18 & $\begin{array}{l}\text { "I just take fish for the table and no more" (36) } \\
\text { "You make sure you're not in the marine reserve when you fish" (102) } \\
\text { "I always catch and release" (105) }\end{array}$ \\
\hline Education & 41 & $\begin{array}{l}\text { "I'm looking to contribute, to educate others, now I'm retired" (255) } \\
\text { "I educate kids on how to care for (this place) and the importance of animals" (360) } \\
\text { "The beauty of the environment here is an opportunity to educate others" (420) }\end{array}$ \\
\hline Advocacy & 19 & $\begin{array}{l}\text { "I'm an environmental advocate. We only act locally" (181) } \\
\text { "Reserves have a positive impact, any argument to the contrary is absurd. I support them and I'm a } \\
\text { fisher" (219) } \\
\text { "I enjoy bird counting. My data can influence decision-makers" (362) }\end{array}$ \\
\hline Informal enforcement & 21 & $\begin{array}{l}\text { "I have approached people and said 'that's an undersize fish' but you have to be careful" (70) } \\
\text { "We always call out if we see fishing boats; I have the fisheries hotline on speed dial" (95) } \\
\text { "It's worthless to have reserves if they don't restrict fishing, so we have to enforce reserves" (281) }\end{array}$ \\
\hline Monitoring & 15 & $\begin{array}{l}\text { "I count the number of people with a clicker, and write down the species that are seen each day" (2) } \\
\text { "I take photos for iNaturalist" (64) } \\
\text { "We do the nudibranch census here each year" (101) }\end{array}$ \\
\hline Preservation & 28 & $\begin{array}{l}\text { "I like to preserve it, to let the marine life recover" (12) } \\
\text { "I learnt to look after the environment in Scouts, to keep it pristine" (293) } \\
\text { "You have to respect what you've got, not damage things, so you can come back" (322) }\end{array}$ \\
\hline Restoration & 75 & $\begin{array}{l}\text { "I always take three for the sea" (95) } \\
\text { "We're an active group that has been cleaning up the beach" (96) } \\
\text { "I bring the grand-kids here to do clean-ups" (255) }\end{array}$ \\
\hline
\end{tabular}

Categories are based on Turnbull et al (2020a)

richness, abundance and biomass of fish, invertebrate and habitat communities, and predictor variables were local stewardship and protection level. We included random intercepts for Year (6 levels), State (5 levels), and Site (56 levels), where Site was nested in State and Year. Data were log-transformed to meet the assumptions of homogeneity of variance. Fish biomass was calculated using constants from the allometric growth equation Biomass $=\mathrm{aL}^{\mathrm{b}}$ (Froese 2017). We used Collaborative and Annotation Tools for Analysis of Marine Imagery (CATAMI) guide version 1.2 (Althaus et al. 2013) to analyse habitat to the morphotaxa level in CoralNet (Beijbom 2012) as we were most interested in the visible and structural aspects of habitat.

Stewardship was calculated for each participant as a continuous variable based on the reported frequency of the seven stewardship actions using the Local Environment Stewardship Indicator (LESI) (Turnbull et al. 2020b) (Table 2). We calculated site stewardship levels as the maximum stewardship score across all participants at a site, due to the importance of "uber-stewards" in directly and indirectly influencing local ecological and social outcomes (Turnbull et al. 2020a).

This study was conducted under the ethics approval of the University of NSW, permit HC180044

\section{Results}

\section{The sustainability spiral}

Our findings are summarised in a new empirically grounded framework comprising a conceptual diagram and spiral model which we name the Sustainability Spiral. The conceptual diagram (Fig. 3a) portrays a virtuous cycle in which institutional and local stewardship combine to improve ecological outcomes, which in turn motivate further stewardship. Multiple iterations of this cycle are portrayed in the new spiral model, enabling visualisation of progress towards sustainability goals over time (Fig. 3b).

\section{Empirical support for the sustainability spiral}

Overall $48 \%$ of our sample identified as female, $58 \%$ of participants regarded themselves as local, participants had been coming to their site for an average of 14.8 years and had visited 7.3 times in the last month. The majority (89\%) of participants reported undertaking one or more stewardship actions at their site (Table 2). 


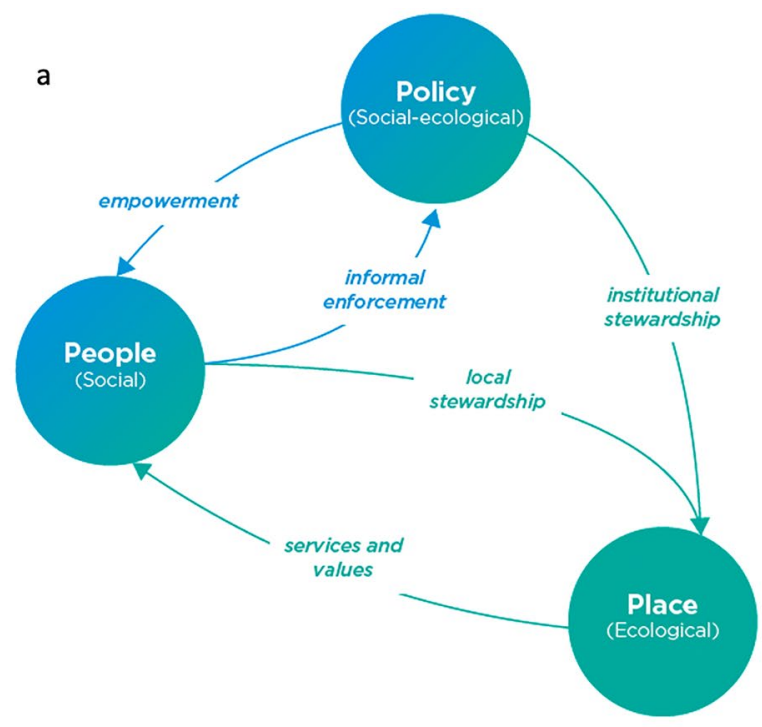

b

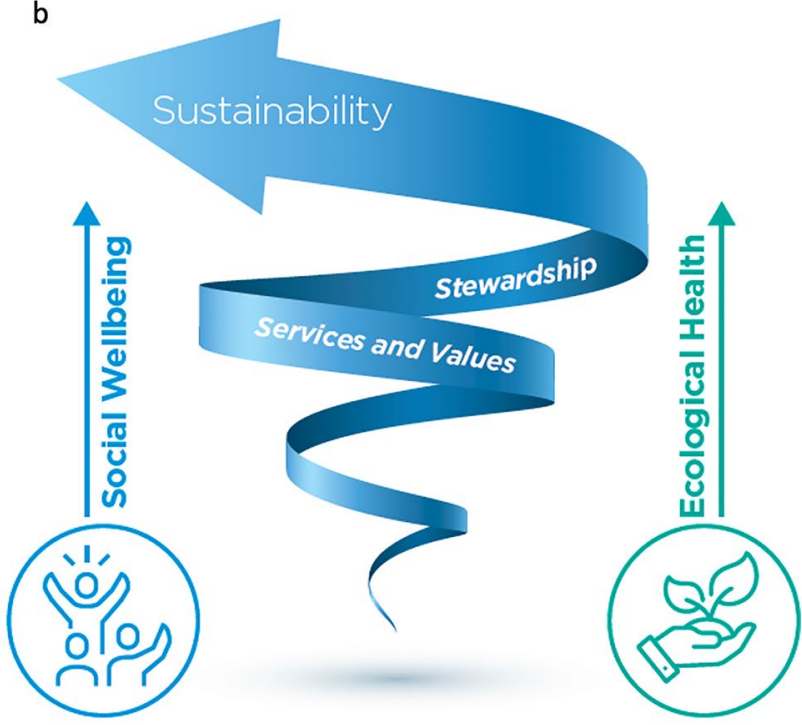

Fig. 3 Sustainability spiral model; a conceptual diagram in which the people-policy sub-cycle empowers local stewardship and improves the effectiveness of institutional stewardship, which combine to drive ecological outcomes in the main social-ecological virtuous cycle. Ecological outcomes result in improved ecosystem services and values, which motivate further stewardship; b spiral model representing multiple iterations of the virtuous cycle over time, progressing towards sustainability goals

When asked to elaborate on the motivation for their stewardship actions, 91\% indicated one or more components of the virtuous cycle (Table 3), and almost half $(43 \%)$ acted to achieve ecological outcomes alone such as protecting marine life from harm. Favoured marine life were primarily fish (valued by $26 \%$ of participants) followed by algae and seagrass (10\%), marine mammals (9\%) and birds (8\%). People who fished at their site valued fish the most (valued by $42 \%$ of fishers). Whilst non-fishers talked more generally about marine life or wildlife (30\%), their focus on fish as favoured marine life was still high (23\%).

Over one quarter (27\%) of people were motivated by social outcomes alone such as swimming in water free of debris, and 30\% were motivated by both social and ecological factors, effectively describing both directions of the virtuous cycle and in many cases longer term sustainability outcomes (Table 3). Over half (55\%) of stewards were motivated by sustainability or related long-term concepts such as preservation for future generations, integrity of nature or ecosystems and reducing unsustainable human impacts.

Our quantitative analyses provided correlative support for this virtuous cycle. Sites with higher maximum local stewardship levels and higher institutional stewardship (fully protected areas) were associated with significantly more fish biomass (Fig. 4c, d). We detected no significant improvement in fish diversity or biomass in partially protected areas compared to open areas. Participants reported undertaking higher levels of local stewardship action at sites with more diverse habitat and when they perceived better marine life at a site $(p<0.05$ for all results, Fig. $4 \mathrm{e}, \mathrm{f}$, and Table S3).

Participants also undertook stewardship actions as a result of the presence of, and to improve the effectiveness of, their local marine protected area. These are generally represented by empowerment and informal enforcement arrows in Fig. 3a, respectively. Stewardship was significantly higher in fully protected areas than in partially protected areas and open areas, but there was no significant difference in stewardship between partially protected areas and open areas (Fig. 4a and Table S3). Empowerment included having effective rules to enforce in fully protected areas, enabling the connection between shore and marine life, and valuing and preserving fully protected areas (Table 4). Informal enforcement was undertaken by over one fifth (21\%) of participants (Table 2) and took the forms of documenting transgressions, speaking with people breaking the rules and sometimes reporting them. Signage also appeared to correspond with increased stewardship of sites, with significantly higher maximum stewardship levels at sites that had more signs promoting local marine life (Fig. 4b and Table S3).

\section{Discussion}

The Sustainability Spiral portrays the mutual interdependency of social and ecological domains in progressing towards sustainability through time, over multiple 
Table 3 Examples of motivations for stewardship, in response to the question "why do you (take these stewardship actions)"?; ecological, social and both; with participant reference number

\begin{tabular}{|c|c|c|}
\hline Ecological motivations $(n=172)$ & Social motivations $(n=109)$ & Social-ecological motivations $(n=120)$ \\
\hline $\begin{array}{l}\text { "Because it's harmful to animals. I've seen } \\
\text { awful impacts on marine life" (237) }\end{array}$ & $\begin{array}{l}\text { "It's a privilege to swim here and see fish" } \\
\text { (17) }\end{array}$ & $\begin{array}{l}\text { "For future generations of animals and humans" } \\
\text { (29) }\end{array}$ \\
\hline $\begin{array}{l}\text { "To help the ocean; humans are mindlessly } \\
\text { exploiting it" (257) }\end{array}$ & $\begin{array}{l}\text { "Preserve it for our children" (48) } \\
\text { "The ocean takes care of us" (79) }\end{array}$ & $\begin{array}{l}\text { "For the integrity of ecosystems, and human } \\
\text { health" (59) }\end{array}$ \\
\hline $\begin{array}{l}\text { "So we don't ruin nature and contribute to its } \\
\text { destruction" (274) }\end{array}$ & $\begin{array}{l}\text { "The diving is important for my business" } \\
\text { (106) }\end{array}$ & $\begin{array}{l}\text { "For sustainability and sustainable fisheries, to } \\
\text { avoid animals ingesting plastic" (138) }\end{array}$ \\
\hline "So the animals don't eat pollution" (347) & "This place is free pleasure, I want to keep it & "Care for the habitat, so other creatures can use \\
\hline "Safeguard the environment" (403) & natural” $(123)$ & it, and other people can enjoy it” (197) \\
\hline \multirow[t]{3}{*}{$\begin{array}{l}\text { "To take care of my local and preserve diver- } \\
\text { sity" (410) }\end{array}$} & "It's part of who I am" (275) & $\begin{array}{l}\text { "Minimal impact is the future, it's the only way } \\
\text { to sustain life" (244) }\end{array}$ \\
\hline & & "It's part of the circle of life" (246) \\
\hline & & $\begin{array}{l}\text { "Water is life, we share a connection with the } \\
\text { ocean" (288) }\end{array}$ \\
\hline
\end{tabular}

Longer term sustainability outcomes, aligned with SDGs (Table 1), are underlined

virtuous cycles. It conveys the dynamic, adaptive nature of social-ecological relationships (Chapin III et al. 2010; Folke et al. 2016) in general terms, describing how effective stewardship moves virtuous cycles upwards towards sustainability, whilst poor stewardship and overexploitation of natural systems result in downward vicious cycles towards unsustainability.

The spiral model is an important contribution to the conceptualisation of stewardship. Existing theoretical models rely on the two-dimensional closed-loop framework and show the relationship between virtuous cycle components, but make it difficult to visualise changes in the status of these components over time. Reframing stewardship to recognise its dynamic, transformative nature is an essential step towards achieving conservation and sustainability goals (Chapin III et al. 2010; Mathevet et al. 2018).

The Sustainability Spiral enables visualisation of the direction of progress and position in time for sustainability overall, or at a more discrete level such as a particular SDG or target. For example, the goal of Life Below Water (SDG \#14) includes the target of protection of $10 \%$ of marine and coastal ecosystems by 2020 . The Sustainability Spiral can be applied for this one component alone, visualised by placing the $10 \%$ goal at the top of the spiral and noting the current position at points in time on the vertical dimension [ $4.4 \%$ in 2015 and $7.4 \%$ in 2020 (UNEP-WCMC 2020)]. The model then encourages elaboration of the stewardship actions that are required (for example, steps to increase the area of ocean under protection and enable local community support) and the values and ecosystem services that motivate progress towards the goal (for example, more fish diversity and biomass, sustainable supply of protein and tourism revenue).

\section{Stewardship}

Numerous studies have found that effective institutional stewardship, in the form of well-managed fully protected areas, results in higher fish biomass and diversity (Costello and Ballantine 2015; Edgar et al. 2014; Turnbull et al. 2018). Our study builds on these results to show that institutional stewardship combines with the stewardship actions of people in the community to result in an even stronger positive association for fish biomass (Fig. 4c). This is in keeping with studies in other settings, for example co-management of tropical reefs (Cinner et al. 2012; Pollnac et al. 2010).

The most frequently reported stewardship action among participants in our study was restoration ( $75 \%$ of participants), primarily through cleaning up debris, followed by educating others ( $41 \%$ of participants) (Table 2 ). These represent direct and indirect stewardship actions, respectively, with the former impacting directly on the environment and the latter potentially raising local stewardship levels by influencing the actions of others (Bennett et al. 2018). The high rates of stewardship reported in our study reflect our broad measure, encompassing seven actions, and provide evidence of substantial pro-environmental behaviour despite the recognised gap between human values, intentions and actual behaviour (Kollmuss and Agyeman 2002). Overall, $89 \%$ of participants were motivated to act on their values and intentions to undertake some form of stewardship. 
Positive local signage relating to marine life, for example showing "what lives here", was significantly related to higher levels of stewardship (Fig. 4b). Previous studies have found that signage can influence pro-environmental behaviour (Martin et al. 2017; Marschall et al. 2017) although the effect can vary depending on presentation, content and placement (Martin et al. 2015). Such signage may flag the presence of social or collective norms for stewardship and, together with compliance signage, may signal the existence of policies focused on preservation vs. exploitation (Goldstein and Cialdini 2007). Social norms can provide a mechanism to reduce consumption of shared resources, for the collective good (Levin 2006). We found no significant relationship between local stewardship and compliance signage (signs explaining the rules); however, compliance signage does improve awareness of regulations (Turnbull et al., 2021) and may, therefore, still act indirectly on ecological outcomes.

\section{Ecological outcomes}

The most direct ecological outcome of combined institutional and local stewardship-more fish-appears to also be the most socially valued ecological factor on the virtuous cycle, and is, therefore, the primary basis for the empirical support for our model (Fig. 4). Participants also valued and were motivated by broader sustainability outcomes including the welfare of and reduction of harm to animals in general, keeping a place 'natural' or 'pristine', and protection from overexploitation and pollution (Table S5). Key supporting themes included the fragility of the environment and the need to respect and care for it, the unsustainable level of human impact, and resulting degradation of ecological integrity, health, abundance and diversity.

Valuing marine life generally, and fish more specifically, was driven primarily by aesthetic, non-extractive reasons. Liking, beauty, nature and watching were all more prevalent as reasons for favouring marine life than catching or eating fish. This reflects the diverse range of coastal users, $82 \%$ of which did not fish in the context of our study, and highlights the importance of considering such non-consumptive stakeholders in coastal studies (Farr et al. 2014)

\section{Social outcomes}

Over half of participants reported undertaking stewardship of the environment to achieve social outcomes such as the enjoyment of observing wildlife, human benefits based on our dependence on nature, identity, preservation for future generations and business (Table S6). Aesthetics, cleanliness and families were key themes in valuing and caring for the environment, as well as directly experiencing wildlife in its natural habitat (Table S6).

These social factors were enabled by healthy natural ecosystems, perpetuated and improved by ongoing stewardship (Fig. 3), as represented in the Sustainability Spiral. Our quantitative results aligned with these findings via the significant relationship between more diverse habitat and the level of local environmental stewardship. We also found a significant positive relationship between the perception that local marine life is better than surrounding areas and higher stewardship activity. Multiple theories propose that behaviour is the result of values and perceptions, for example the Theory of Planned Behaviour (Ajzen 1991), supporting a potential direction of causality from ecological improvement to perception of this improvement and finally stewardship behaviour.

\section{Policy and management implications}

Policies for sustainability through institutional stewardship, in the form of fully protected areas, empowered local stewardship and directly improved ecological outcomes in our study. Policies, therefore, synergised with the actions of local community stewards to deliver an even stronger virtuous cycle (Fig. 3a). Protection-related policies were highlighted as important enablers of sustainability by participants undertaking stewardship, including the presence of protected areas in general and fully protected areas in particular (10\% of participants each), effective rules and regulations (7\%), effective management (6\%), enablement of science and research (3\%) and prevention of user conflict through zoning (3\%).

Fully protected areas were associated with higher levels of maximum and individual local stewardship (Table S4), enabling the realisation of the desire for improving ecological health. They empowered local stakeholders to undertake advocacy, education, and informal enforcement (Table 2). Informal enforcement, both alone and in combination with formal enforcement, can improve the effectiveness of protected areas (Santis and Chávez 2015). Empowerment at individual and collective scales is essential for the transformation that is necessary to achieve global sustainability (Andrijevic et al. 2020; Messerli et al. 2019).

One component of our model - the policy-to-place relationship-is well documented in other studies (for example, Edgar et al 2014) and so the direction of causality is 

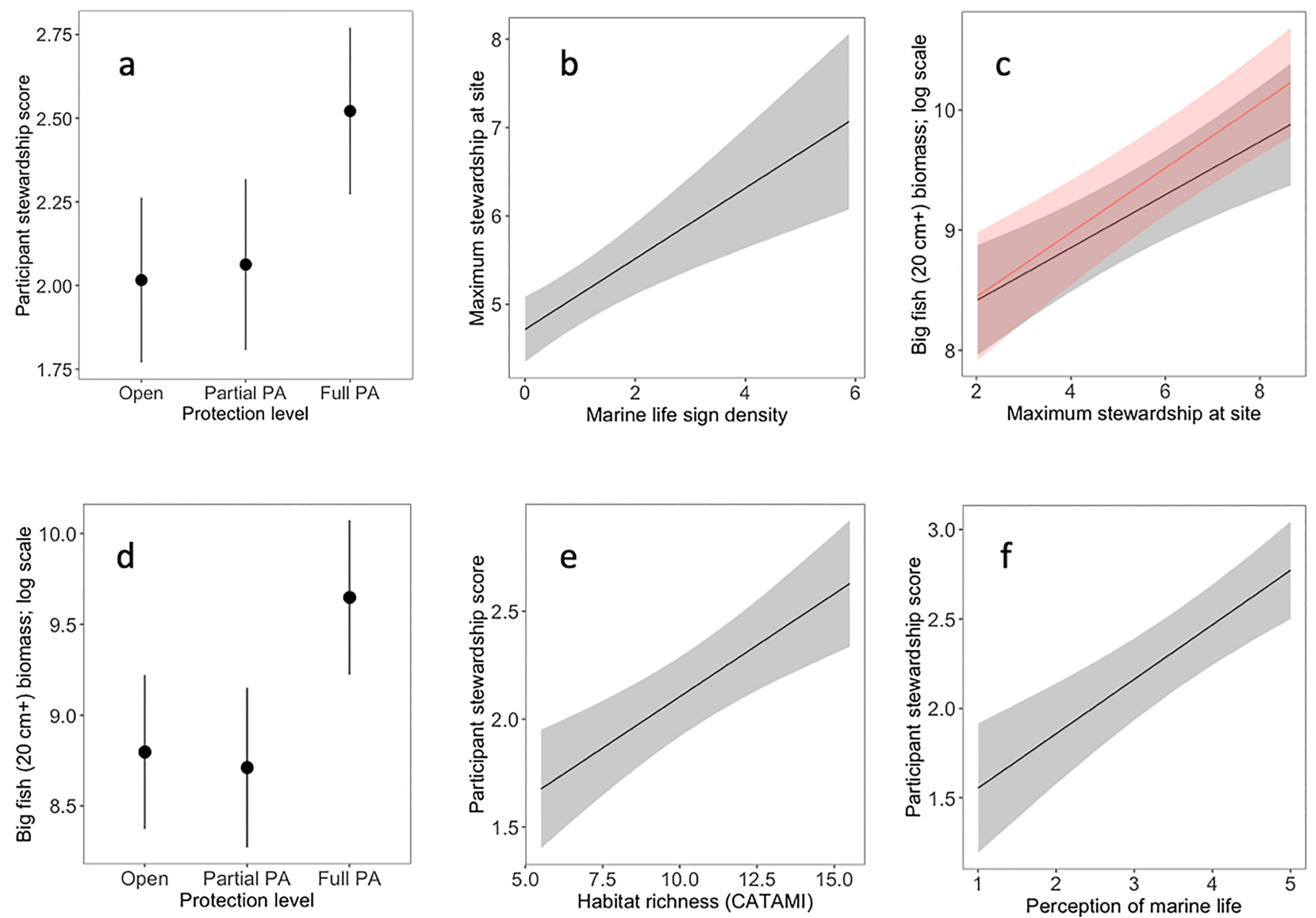

g
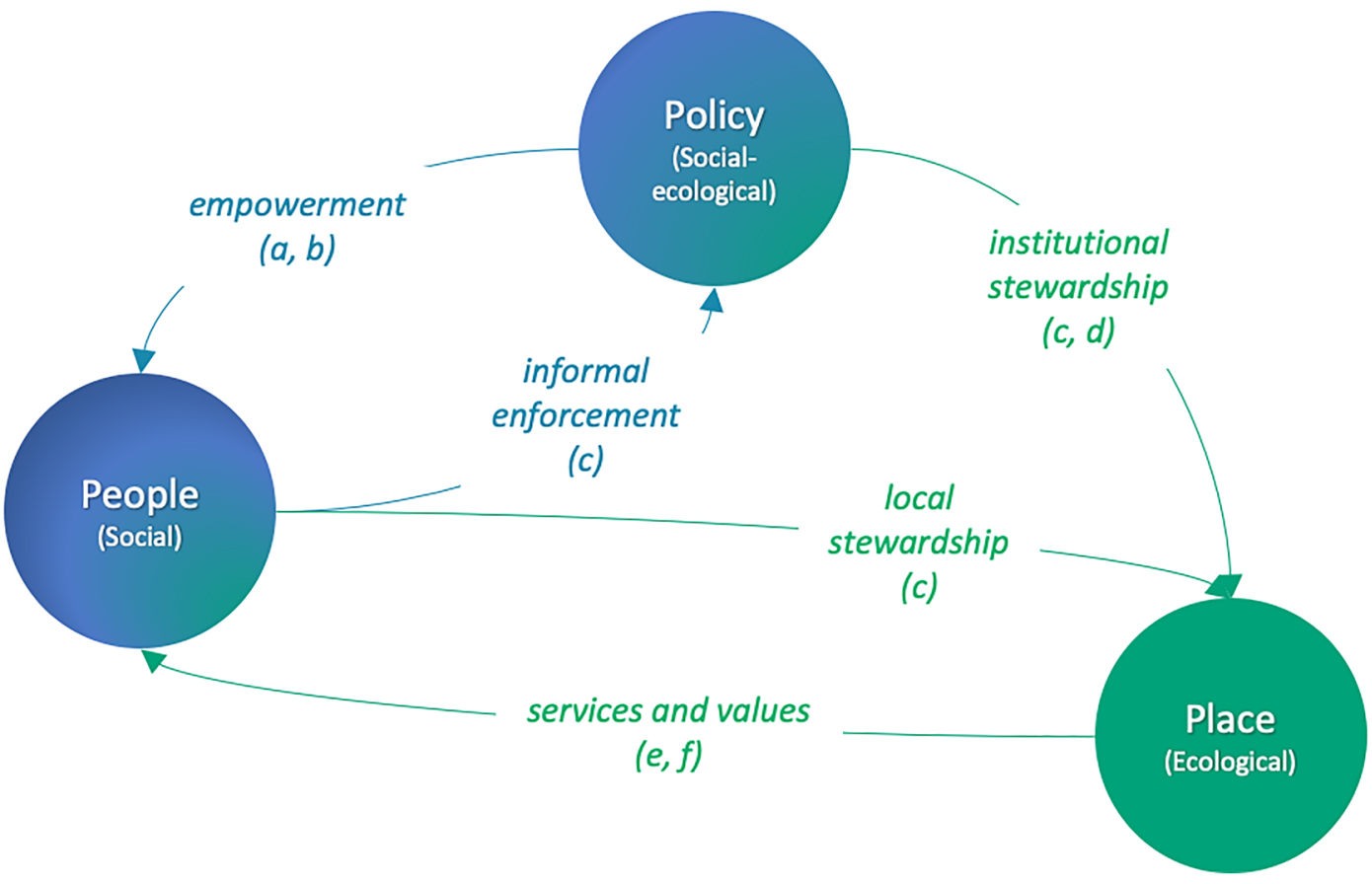
4Fig. 4 Linear model plots of quantitative empirical support for the virtuous cycle of the Sustainability Spiral with bands showing standard error; a higher participant stewardship levels empowered by fully protected areas $(p=0.027)$; b higher maximum stewardship levels at sites with more marine life-related signage $(p=0.034)$; $\mathbf{c}$ higher big fish biomass at sites that have high maximum local stewardship, grey: all sites and red: fully protected areas only $\left(p_{\text {all sites }}=0.03\right.$ and $p_{\mathrm{fpa}}=0.009$ ); $\mathbf{d}$ higher big fish biomass in fully protected areas $(p=0.05)$; e higher stewardship levels at sites with more diverse habitat $(p=0.033)$; $\mathbf{f}$ higher stewardship activity when participants perceived better marine life at a site $(p=0.007)$; and $\mathbf{g}$ significant results mapped onto the Sustainability Spiral conceptual diagram by their panel letters $(\mathbf{a}-\mathbf{f})$

supported in the literature. The other four relationships all entail social factors which we support in this study with qualitative evidence in Tables 3 and 4 to support our interpretation of causality. Further research may target each of these relationships to further explore them with new statistical methods and designs.

We designed our study to focus on local contexts and draw conclusions in aggregate at a semi-continental scale. Our qualitative results provide insight into individuals and their motivations at the local level, and our quantitative results provide evidence for the large-scale relationships between people, policy and place. Global environmental problems need action at multiple scales (Sterner et al. 2019) but solutions are often best implemented at local scales (Duarte et al. 2020). Our study illustrates the operation of virtuous cycles via people undertaking stewardship at their local coastal place, enabled by effective higher level policy.

Whilst we developed our model for broad application, our general language may need refinement to suit the prevailing terminology in other settings. We distinguish between local stewardship - arising from the motivations and actions of individuals and groups at a local level; and institutional stewardship-driven by higher level authorities through policy and regulation. These terms are in keeping with prior research such as the co-management of tropical marine social-ecological systems (Cinner et al. 2012), although the two forms of stewardship may be hybridised as combined customary and modern management institutions (Cinner and Aswani 2007). We believe further research is warranted to explore the concepts, framings and dynamics of virtuous cycles in other social-ecological contexts.

\section{Conclusion}

Today, human society and our biosphere urgently need to achieve sustainability through effective earth stewardship (Folke et al. 2016; Steffen et al. 2011). In this study, we conclude that effective institutional and local stewardship can drive iterative virtuous cycles of improving social and ecological outcomes, which over time may progress towards sustainability. Pursuit of the UN 2030 Agenda requires such virtuous cycles to conserve and protect wildlife and the environment, maintain natural resources and preserve the long-term integrity of our social-ecological systems. This depends on more positive, generally applicable ways of conceptualising social-ecological systems, such as the Sustainability Spiral. Such framings are essential to engage and facilitate collaborations with stakeholders, enable transformation, and pursue mutually desirable outcomes for a sustainable future.

Table 4 Examples of policy-related explanations offered by participants regarding their stewardship actions and why they were undertaken, with participant reference number in brackets

\begin{tabular}{|c|c|}
\hline Empowerment $(n=35)$ & Informal enforcement $(n=92)$ \\
\hline $\begin{array}{l}\text { "Because it's a sanctuary zone. It's connected-shore to marine life" } \\
\text { ( } 435) \\
\text { "Because (the fully protected area) should be enforced; we want to have } \\
\text { places protected" (235) } \\
\text { "Our sanctuaries are so small, any transgression is a big issue" (183) } \\
\text { "Because it's precious to have a marine park so close to the city, with } \\
\text { wild animals in it" (256, in a fully protected area) } \\
\text { "To preserve the area, because it's a fish sanctuary" (272) } \\
\text { "(The partially protected area) should be a sanctuary... at the moment } \\
\text { the only protections the marine life receive... is from locals defending } \\
\text { fish, gastropods and weed themselves" (19) }\end{array}$ & $\begin{array}{l}\text { "We always call out if we see fishing boats; I have the fisheries hotline } \\
\text { on speed dial. I often take photos of boats fishing in the reserve." } \\
\text { ( } 98 \text { ) } \\
\text { "A fishing boat came in early in the morning, they were standing there } \\
\text { in the middle of the bay, blatantly fishing. We yelled at them and told } \\
\text { them there were big fines, and they moved" (2) } \\
\text { "I ask people not to spear the fish" (278) } \\
\text { "You can only go down and try to explain the situation to people, even } \\
\text { if they give you a gobful." (17) } \\
\text { "A family was fishing off rocks in the reserve, I spoke to them" (282) }\end{array}$ \\
\hline
\end{tabular}


Supplementary Information The online version contains supplementary material available at https://doi.org/10.1007/s11625-021-00981-4.

Open Access This article is licensed under a Creative Commons Attribution 4.0 International License, which permits use, sharing, adaptation, distribution and reproduction in any medium or format, as long as you give appropriate credit to the original author(s) and the source, provide a link to the Creative Commons licence, and indicate if changes were made. The images or other third party material in this article are included in the article's Creative Commons licence, unless indicated otherwise in a credit line to the material. If material is not included in the article's Creative Commons licence and your intended use is not permitted by statutory regulation or exceeds the permitted use, you will need to obtain permission directly from the copyright holder. To view a copy of this licence, visit http://creativecommons.org/licenses/by/4.0/.

\section{References}

Ajzen I (1991) The theory of planned behavior. Organ Behav Hum Decis Process 50(2):179-211

Althaus F, Hill N, Edwards L, Ferrari R, Case M, Colquhoun J (2013) CATAMI classification scheme for scoring marine biota and substrata in underwater imagery-a pictorial guide to the collaborative and annotation tools for analysis of marine imagery and video (CATAMI) classification scheme. Version 1. CATAMI Technical Working Group. http://catami.org/classification. Accessed Jan 2020

Andrijevic M, Cuaresma JC, Muttarak R, Schleussner C-F (2020) Governance in socioeconomic pathways and its role for future adaptive capacity. Nat Sustain 3(1):35-41

Beijbom O, Edmunds PJ, Kline DI, Mitchell BG, Kriegman D (2012) Automated annotation of coral reef survey images. In Computer Vision and Pattern Recognition (CVPR). Paper presented at the IEEE Conference

Bennett S, Wernberg T, Connell SD, Hobday AJ, Johnson CR, Poloczanska ES (2016) The 'Great Southern Reef': social, ecological and economic value of Australia's neglected kelp forests. Mar Freshw Res 67(1):47-56

Bennett NJ, Whitty TS, Finkbeiner E, Pittman J, Bassett H, Gelcich S, Allison EH (2018) Environmental stewardship: a conceptual review and analytical framework. Environ Manag 61(4):597-614

Binder CR, Hinkel J, Bots PW, Pahl-Wostl C (2013) Comparison of frameworks for analyzing social-ecological systems. Ecol Soc $18(4)$

Bryman A (2016) Social research methods. Oxford University Press

Chapin FS III, Carpenter SR, Kofinas GP, Folke C, Abel N, Clark WC, Olsson P, Smith DMS, Walker B, Young OR, Berkes F (2010) Ecosystem stewardship: sustainability strategies for a rapidly changing planet. Trends Ecol Evol 25(4):241-249

Chapin FS, Power ME, Pickett ST, Freitag A, Reynolds JA, Jackson RB, Lodge DM, Duke C, Collins SL, Power AG, Bartuska A (2011) Earth Stewardship: science for action to sustain the human-earth system. Ecosphere 2(8):1-20

Cinner JE, Aswani S (2007) Integrating customary management into marine conservation. Biol Cons 140(3):201-216

Cinner JE, McClanahan TR, MacNeil MA, Graham NA, Daw TM, Mukminin A, Feary DA, Rabearisoa AL, Wamukota A, Jiddawi N, Campbell SJ (2012) Comanagement of coral reef social-ecological systems. Proc Natl Acad Sci 109(14):5219-5222
Cinner JE, Zamborain-Mason J, Gurney GG, Graham NA, MacNeil MA, Hoey AS, McClanahan TR (2020) Meeting fisheries, ecosystem function, and biodiversity goals in a human-dominated world. Science 368(6488):307-311

Costello MJ, Ballantine B (2015) Biodiversity conservation should focus on no-take Marine Reserves: $94 \%$ of marine protected areas allow fishing. Trends Ecol Evol 30(9):507-509

DESA UN (2016) Transforming our world: the 2030 agenda for sustainable development. Division for sustainable development goals, New York, NY, USA

Duarte CM, Agusti S, Barbier E, Britten GL, Castilla JC, Gattuso JP, Fulweiler RW, Hughes TP, Knowlton N, Lovelock CE, Lotze HK (2020) Rebuilding marine life. Nature 580(7801):39-51

Dudley N, Shadie P, Stolton S (2013) Guidelines for applying protected area management categories including IUCN WCPA best practice guidance on recognising protected areas and assigning management categories and governance types. Best practice protected area guidelines series (21)

Edgar GJ, Stuart-Smith RD, Willis TJ, Kininmonth S, Baker SC, Banks S, Barrett NS, Becerro MA, Bernard AT, Berkhout J, Buxton CD (2014) Global conservation outcomes depend on marine protected areas with five key features. Nature 506(7487):216-220

Farr M, Stoeckl N, Beg RA (2014) The non-consumptive (tourism) 'value' of marine species in the Northern section of the Great Barrier Reef. Mar Policy 43:89-103

Folke C, Biggs R, Norström AV, Reyers B, Rockström J (2016) Social-ecological resilience and biosphere-based sustainability science. Ecol Soc 21(3)

Froese RAPD (2017) FishBase. World Wide Web electronic publication. www.fishbase.org, version (06/2017)

Glaser BG, Strauss AL, Strutzel E (1968) The discovery of grounded theory; strategies for qualitative research. Nurs Res 17(4):364

Goldstein NJ, Cialdini RB (2007) Using social norms as a lever of social influence. The science of social influence: advances and future progress, $\mathrm{p}$ 167-192

Kollmuss A, Agyeman J (2002) Mind the gap: why do people act environmentally and what are the barriers to pro-environmental behavior? Environ Educ Res 8(3):239-260

Lerner SC (ed) (1993) Environmental stewardship: Studies in active earthkeeping, vol 39. Department of Geography, University of Waterloo

Levin SA (2006) Learning to live in a global commons: socioeconomic challenges for a sustainable environment. Ecol Res 21(3):328-333

Marschall S, Granquist SM, Burns GL (2017) Interpretation in wildlife tourism: assessing the effectiveness of signage on visitor behaviour at a seal watching site in Iceland. J Outdoor Recreat Tour 17:11-19

Martin CL, Momtaz S, Jordan A, Moltschaniwskyj NA (2015) An assessment of the effectiveness of in-situ signage in multiple-use marine protected areas in providing information to different recreational users. Mar Policy 56:78-85

Martin VY, Weiler B, Reis A, Dimmock K, Scherrer P (2017) 'Doing the right thing': how social science can help foster pro-environmental behaviour change in marine protected areas. Mar Policy 81:236-246

Masterson VA, Vetter S, Chaigneau T, Daw TM, Selomane O, Hamann M, Wong GY, Mellegård V, Cocks M, Tengö M (2019) Revisiting the relationships between human well-being and ecosystems in dynamic social-ecological systems: Implications for stewardship and development. Glob Sustain 2

Mathevet R, Bousquet F, Raymond CM (2018) The concept of stewardship in sustainability science and conservation biology. Biol Cons 217:363-370

Messerli P, Kim EM, Lutz W, Moatti JP, Richardson K, Saidam M, Smith D, Eloundou-Enyegue P, Foli E, Glassman A, Licona GH 
(2019) Expansion of sustainability science needed for the SDGs. Nat Sustain 2(10):892-894

Moskell C, Allred SB (2013) Integrating human and natural systems in community psychology: an ecological model of stewardship behavior. Am J Community Psychol 51(1-2):1-14

Ostrom E (2009) A general framework for analyzing sustainability of social-ecological systems. Science 325(5939):419-422

Pollnac R, Christie P, Cinner JE, Dalton T, Daw TM, Forrester GE, Graham NA, McClanahan TR (2010) Marine reserves as linked social-ecological systems. Proc Natl Acad Sci 107(43):18262-18265

Powell J, Selman P, Wragg A (2002) Protected areas: reinforcing the virtuous circle. Plan Pract Res 17(3):279-295. https://doi.org/10. 1080/026974502200005643

Preiser R, Pereira LM, Biggs RO (2017) Navigating alternative framings of human-environment interactions: variations on the theme of 'Finding Nemo.' Anthropocene 20:83-87

QSR (2018) nVivo version 12.1.0.249 Pro edition

R Core Team (2018) R: a language and environment for statistical computing. In: R foundation for statistical computing, Vienna

Raymond CM, Singh GG, Benessaiah K, Bernhardt JR, Levine J, Nelson H, Turner NJ, Norton B, Tam J, Chan KM (2013) Ecosystem services and beyond: using multiple metaphors to understand human-environment relationships. Bioscience 63(7):536-546

RLS (2016) Standardised survey procedures for monitoring rocky and coral reef ecological communities. http://reeflifesurvey. com/wp-content/uploads/2015/07/NEW-Methods-Manual_ 150815.pdf

Santis O, Chávez C (2015) Quota compliance in TURFs: an experimental analysis on complementarities of formal and informal enforcement with changes in abundance. Ecol Econ 120:440-450

Scholz RW, Binder CR (2011) The HES Framework. In: Environmental literacy in science and society: from knowledge to decisions, Cambridge University Press, pp 453-462

Selman P, Knight M (2006) On the nature of virtuous change in cultural landscapes: exploring sustainability through qualitative models. Landsc Res 31(3):295-307
Smeets E, Weterings R (1999) Environmental indicators: typology and overview

Steffen W, Persson Å, Deutsch L, Zalasiewicz J, Williams M, Richardson K, Crumley C, Crutzen P, Folke C, Gordon L, Molina M (2011) The Anthropocene: from global change to planetary stewardship. AMBIO 40(7):739-761

Sterner T, Barbier EB, Bateman I, van den Bijgaart I, Crépin AS, Edenhofer O, Fischer C, Habla W, Hassler J, Johansson-Stenman O, Lange A (2019) Policy design for the Anthropocene. Nat Sustain 2(1):14-21

Tidball KG, Metcalf S, Bain M, Elmqvist T (2017) Community-led reforestation: cultivating the potential of virtuous cycles to confer resilience in disaster disrupted social-ecological systems. Sustain Sci. https://doi.org/10.1007/s11625-017-0506-5

Turnbull JW, Esmaeili YS, Clark GF, Figueira WF, Johnston EL, Ferrari R (2018) Key drivers of effectiveness in small marine protected areas. Biodivers Conserv 27(9):2217-2242

Turnbull JW, Johnston EL, Kajlich L, Clark GF (2020) Quantifying local coastal stewardship reveals motivations, models and engagement strategies. Biol Conserv 249:108714

Turnbull JW, Johnston EL, Clark GF (2020) LESI: a quantitative indicator to measure local environmental stewardship. Review 7:101141

Turnbull JW, Johnston EL, Clark GF (2021) Evaluating the social and ecological effectiveness of partially protected marine areas. Conserv Biol. https://doi.org/10.1111/cobi.13677

UN Secretary General; Independent Group of Scientists (2019) Global Sustainable Development Report 2019: the future is now-science for achieving sustainable development. United Nations, New York

UNEP-WCMC and IUCN (2020) Marine protected planet [On-line], Cambridge, UK: UNEP-WCMC and IUCN, www.protectedplanet. net. Accessed Aug 2020

Publisher's Note Springer Nature remains neutral with regard to jurisdictional claims in published maps and institutional affiliations. 